\title{
Spatial data availability and its implications for sustainable development of the Brazilian Amazon
}

\author{
Silvana Amaral • Julio Cesar Lima D'Alge
}

Received: 4 May 2009/Accepted: 23 September 2009/Published online: 21 November 2009

(C) Springer-Verlag 2009

\begin{abstract}
In the Amazonia region, general policy based on sustainable development must be adopted to counterbalance natural conservation and the needs of people. To discuss and monitor the regional development requires a significant variety of spatial data. However, making data available is not simple and various solutions usually are presented in non-standardized and non-interchangeable databases. This paper presents an overview of spatial data available for the Amazonia region, and initiatives of data dissemination systems, considering various geographical scales and data access. From this general perspective, we discuss some ideas about the importance of spatial data for sustainability and suggest interactive systems that could contribute to local development and environmental conservation. The limitation on the promotion of spatial information and data sharing in Amazonia is neither computational nor technological. Rather, it is a matter of informing those who generate the data about the benefits of knowledge as a public good and promoting collaborative work. Creating a convergent spatial consciousness about the territory, and bringing together every environmental player, is a step towards the discussion and planning of the sustainable development of the Amazonia.
\end{abstract}

Keywords Amazonia - Data dissemination systems . Geospatial data availability $\cdot$ Sustainability

Communicated by: H.A. Babaei

S. Amaral $(\bowtie) \cdot J$. Cesar Lima D’Alge

Instituto Nacional de Pesquisas Espaciais-INPE,

Av. dos Astronautas n ${ }^{\circ} 1758$,

CEP 12227-010 São José dos Campos, SP, Brazil

e-mail: silvana@dpi.inpe.br

J. Cesar Lima D'Alge

e-mail: julio@dpi.inpe.br

\section{Introduction}

The Brazilian Amazon occupies 5 million $\mathrm{km}^{2}$ and comprises the largest preserved contiguous tropical rain forest in the world: a forested area of approximately 4 million $\mathrm{km}^{2}$. In the last decades, the region has experienced intense transformation processes in both physical and human aspects. Deforestation studies estimated a rate of $11,968 \mathrm{~km}^{2}$ of forest conversion between 2007 and 2008 (INPE 2009a). Official census data estimated that there were 14,623,316 people living in the states of the Brazilian Northern region in 2007, which comprises $7.9 \%$ of the Brazilian population, in contrast to the $6.6 \%$ that was verified in 1970 (IBGE 2008a).

General policy based on sustainable development must be adopted to counterbalance natural conservation and the needs of people who live in the region. In order to discuss and monitor the regional development, several research initiatives and data dissemination systems focused on Amazonia have been proposed. However, making data available is not simple and varying solutions usually appear in non-standardized and non-interchangeable databases.

This paper aims to present a general survey of geographical data sources that are freely available for the Brazilian Amazonia region that could be used as basic information, either for scientific research projects, for initiatives of conservation/development planning and monitoring, and also for spatial data infrastructures. We also described the existing data dissemination systems that integrate the basic geographical data for different objectives throughout the Amazonia region. Finally, based on fieldwork observation, we present some ideas about the importance of spatial data for sustainability in Amazonia, and how interactive systems could be designed to use information on the benefits to the local community, 
providing for environmental conservation and improvements in quality of life.

\section{Spatial data availability for Amazonia}

There are significant geographical spatial data provided by the official governmental agencies at regional and municipal scales for the Legal Amazon. However, considerable effort is required to gather and integrate all of these data in a spatial database. Information is spread out between several institutions, the data format varies, and there are different interfaces for data access. Table 1 presents a summary of this individual geographical data, the URL general reference, and the data source, generally describing the data type, resolution, scale date, and some details about the facilities and limitations when accessing the data. The following text comments on the Geographical Data list presented in Table 1.

The geopolitical boundaries for the Amazonian territory can be accessed from IBGE-Instituto Brasileiro de Geografia e Estatística, the agency responsible for official statistics and geography. To cover Brazilian Legal Amazonia, depending on data scale and type, it is necessary to mosaic the files since they are provided by federal units (states). Municipalities' limits from 2000 up to 2007 (political division compatible with the last official population and agronomical counting) are available, and that is particularly important for the Amazonia, where new municipalities were created throughout the last few decades. Non-spatial information, like demographic variables and socioeconomic conditions, must be further accessed.

Data from official surveys, from both the Population and Agricultural Census (or statistical counting), are available in table format, aggregated by territorial limits such as census-sector or municipality. In a GIS system, users should link these tables to the corresponding spatial information (the geographical limits of municipality, census-sector, etc). Considering that a large number of variables are available, it is essential to previously select the relevant variables for the purpose of the application.

It is also possible to consult the IBGE database, which contains all of the statistical information and visualized maps for each variable (cartograms) by municipality. Original data can be downloaded as tables.

The Brazilian Institute for Geography and Statistics (IBGE) also made available most of the basic geographical mapping, such as geopolitical limits, geology, geomorphology, soils, and vegetation. Unfortunately, for some scales (most of 1:250,000 data), thematic maps still remain in a format inadequate for geographical integration (pdf format). Planimetric maps can also be accessed at scales ranging from $1: 25,000$ to $1: 100,000$ in various formats (pdf, dgn, shapefiles, tiff). Geographical data can also be displayed and browsed using an interactive map server (IBGE 2008b) from which data can be downloaded as well. These are the essential data sets, but it is still necessary to do additional work to gather all the data needed to create a particular database for a specific application or research.

Since the SRTM (Shuttle Radar Topography Mission) Project in 2000 provided imagery for the Earth's surface, topographical data has become readily available. Derived topographic variables, as slope and aspect, and geomorphometrics, can be accessed for the entire Brazilian territory in the Topodata database, developed at INPE-Instituto Nacional de Pesquisas Espaciais - the agency that works with satellite technology and research. There is the inconvenience of a data download of a large number of tiles to cover the Brazilian Amazon, with $30 \mathrm{~m}$ of spatial resolution.

From the water agency ANA-Agência Nacional de Águas - the HidroWeb system enables access to hydrological data for every basin in Brazil. Spreadsheets containing rivers or rainfall information can be downloaded, as well as the limits of water basins and water bodies. However, the interface requires some specific knowledge about the area of interest and the data can be downloaded as text files or in a database format (DBF).

In the Amazon, the limits of properties and land tenure documentation are critical. There is an urgent demand for a general register of land properties (Acervo Fundiário Digital ${ }^{1}$, which INCRA - Instituto Nacional de Colonização e Reforma Agrária-the agency responsible for agrarian reform, planned to launch by the end of 2009 . The agency responsible for environmental conservation, IBAMA-Instituto Brasileiro do Meio Ambiente e dos Recursos Naturais Renováveis-systematized a database where official Settlements Projects (referring to 2006) data can be accessed. The more recent information available about the public land properties is the limit for the Conservation Units (UCs) and the Indian Territories (TIs), for which the updated geographical boundaries and the non-spatial properties can be accessed from ICMBio (Instituto Chico Mendes de Conservação da Biodiversidade), the agency responsible for biodiversity conservation, and FUNAI-Fundação Nacional do Índio-the agency responsible for Indian issues, respectively.

From the Transport Ministry, geographical data about the presence of infrastructure can be accessed and, additionally, there is information about fluxes between ports, roads, and airports (tables). Even though the data comes from 2006/ 2007 , and it is necessary to download the whole database at

\footnotetext{
$\overline{1}$ http://www.incra.gov.br/portal/index.php?option=com_content $\&$ view $=$ article\&id=12492:realidade-fundiaria-do-pais-podera-serconhecida-pela-internet\&catid=1:ultimas $\&$ Itemid $=278$
} 
once, it can be used as a reliable reference regarding the presence of infrastructure.

There is a substantial amount of data and information related to weather and climate conditions available for Brazil, provided by CPTEC - Centro de Previsão de Tempo e Estudos Climáticos - an INPE department responsible for climatic studies and weather forecasting. However, the number of meteorological stations in the Amazon is not comparable to the south/southeast area, which makes it difficult to access detailed meteorological data, such as, for example, rainfall distribution. Weather and climate data are generally available for grids with more than $50 \mathrm{~km}$ of spatial resolution.

Brazilian satellite imagery data with intermediate spatial resolution is available from INPE's catalogue. Historical data of Landsat/MSS images $(80 \mathrm{~m})$ from 1973-1978 can be obtained, as well as recent imagery data of Landsat/TM and ETM (30 m) from 1985-2009, of Landsat/ETM (30 m) images from 1999-2003, from CBERS (China-Brazil Earth Resource Satellite) images of CBERS/WFI $(250 \mathrm{~m})$ from 2004-2009, and CBERS/CCD (20 m), and of CBERS/HRC $(5 \mathrm{~m})$ from 2008-2009. These images are suitable for local scales around to $1: 250,000$ (MSS, ETM, TM and CCD), but requires geocoding and mosaic processing to cover large areas.

From the Amazon Forest Monitoring by Satellite Project of INPE, a single pass annual coverage of geocoded Landsat images for the entire Amazonia can be obtained from the PRODES system (INPE 2009a). Since 2000, PRODES maps deforestation areas larger than $6.25 \mathrm{ha}$, and makes them available for visualization and download (tiff format or shapefiles). DETER and DEGRAD systems complement the Amazon monitoring program. DETER, based on MODIS imagery ( $250 \mathrm{~m}$ spatial resolution), was created to identify all of the changes in forest cover, seeking to identify even intermediate stages of the deforestation process, producing fortnight warnings of deforested area larger than 25 ha (INPE 2009b). DEGRAD system maps forest degradation in areas larger than 6.25 ha (INPE 2009c), the type of deforestation that occurs before the final clear-cut of the forest cover, which is already mapped at PRODES maps.

Since 2007, IMAZON-Instituto do Homen e Meio Ambiente da Amazônia-a non-governmental organization that performs research in the Amazonia, implemented the SAD - Sistema de Alerta de Desmatamento- a deforestation monitoring system also based on MODIS imagery that maps deforestation areas larger than 0.012 ha on a monthly basis (Souza et al. 2009). Even though it uses the same satellite data, a different algorithm is used for image classification, and results can be slightly different than those of the DETER system.

Forest fires are another important subject in the Amazonia region. Even though they are prohibited by law, fires are still regularly used to clear areas after deforestation and to renew pastures. Based on meteorological satellites, INPE monitors forest fires in Brazil daily since 1998. From the QUEIMADAS system, fires foci are produced based on 19 satellites and can be visualized or downloaded (INPE 2009d).

For data sets acquired at more detailed scales, such as from 1:250,000 to 1:2,000, geographical data are scarcer and usually collected by specific scientific projects and academic theses, or are produced by municipal institutions for local purposes. Geographical data do exist, but accessing them is not straightforward.

Using biodiversity data as an example, it is easier to get Brazilian plant information from international databases, such as from the New York Botanical Garden (NYBG 2008) or from the Missouri Botanical Garden (MOBOT 2008), than from the Brazilian herbarium of the northern region. At INPA-Instituto Nacional de Pesquisas na Amazônia-the Brazilian institutes for research in Amazonia, botanical data are still being digitized. (Herbário INPA 2008). In the state of Pará, the herbarium of MPEGMuseu Paraense Emílio Goeldi (Herbarium 2008) - provided information without geographical coordinates, and there are sensitive data which are not published for general users.

Despite the general scientific production, data from surveys are hard to find, gather, and integrate. For studies of forest biomass and dynamics, the Amazon Forest Inventory Network (RAINFOR) proposes data sharing among collaborative researchers (RAINFOR 2008). For other non-participant users, data must be requested from the researchers, following a protocol in which there is a coauthoring commitment for any publication. Even data from surveys supported by the Brazilian government, such as the Research Program in Biodiversity-PPBIO - are shared only among collaborating researchers, following the same distribution protocol (PPBio 2008).

For more detailed scales, at a municipal basis, several initiatives are studying and generating relevant data for the Amazon region. Non-governmental institutions, governmental projects, universities, and even municipal government departments play very important roles and provide data for planning purposes. But these data are neither systematized nor easily accessed.

\section{Data dissemination systems available for Amazonia}

The Brazilian Spatial Data Infrastructure (INDE) specifies standard protocols and norms to promote organized generation, storage, access, and usage of geospatial data from official government sources for the benefit of Brazilian development (Presidência da República 2008). A 

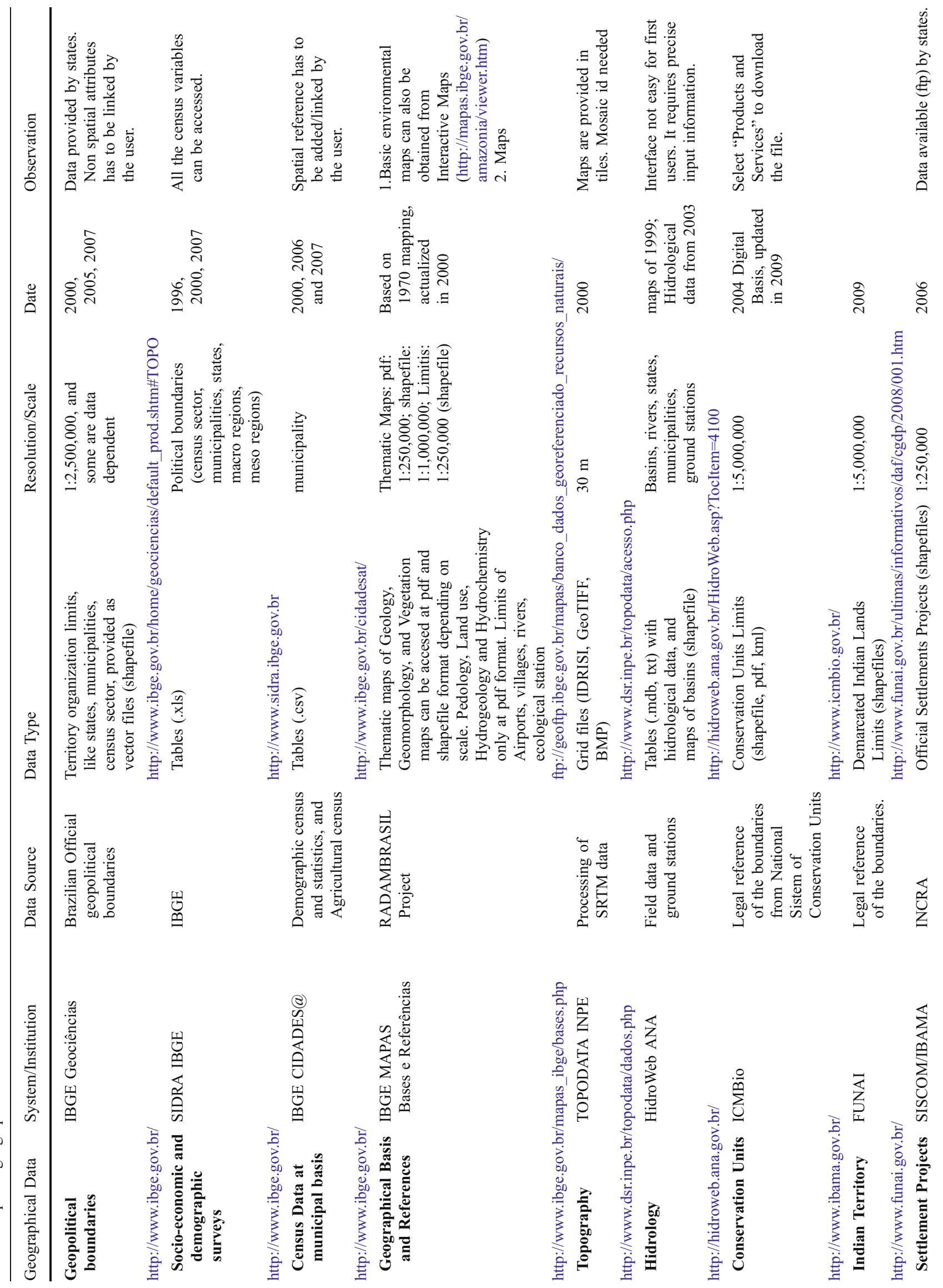


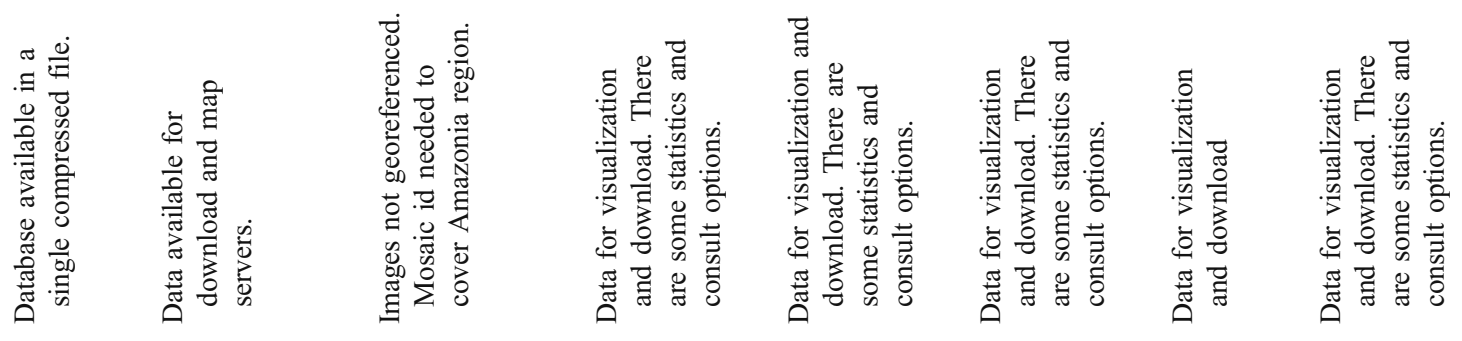

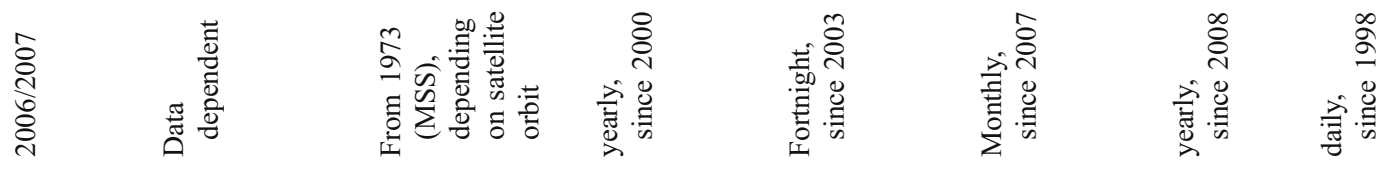

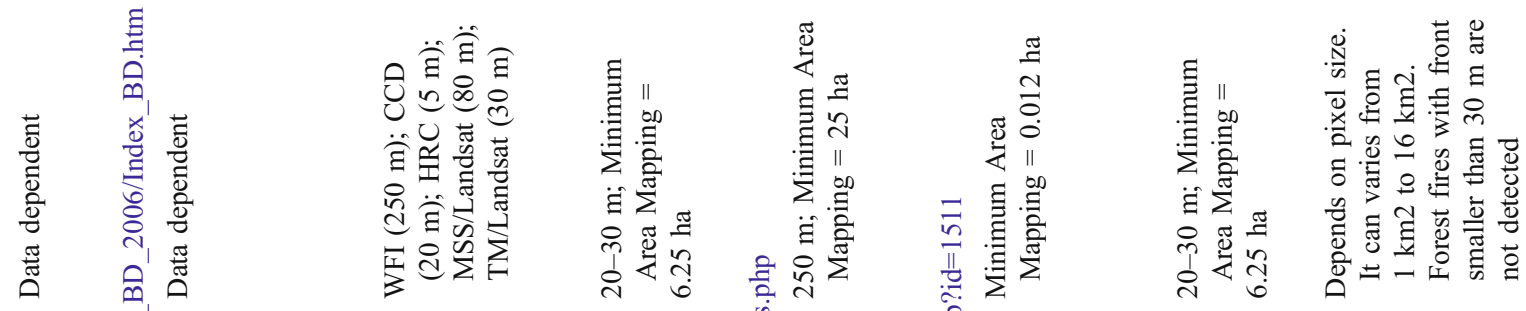

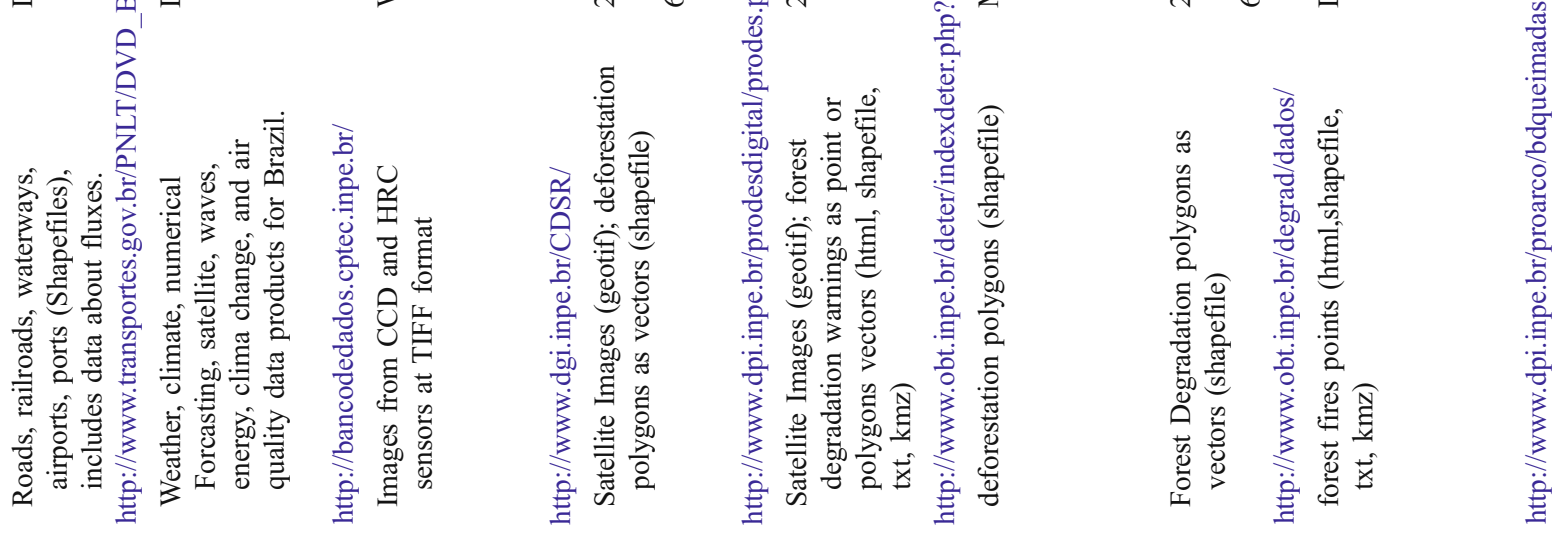
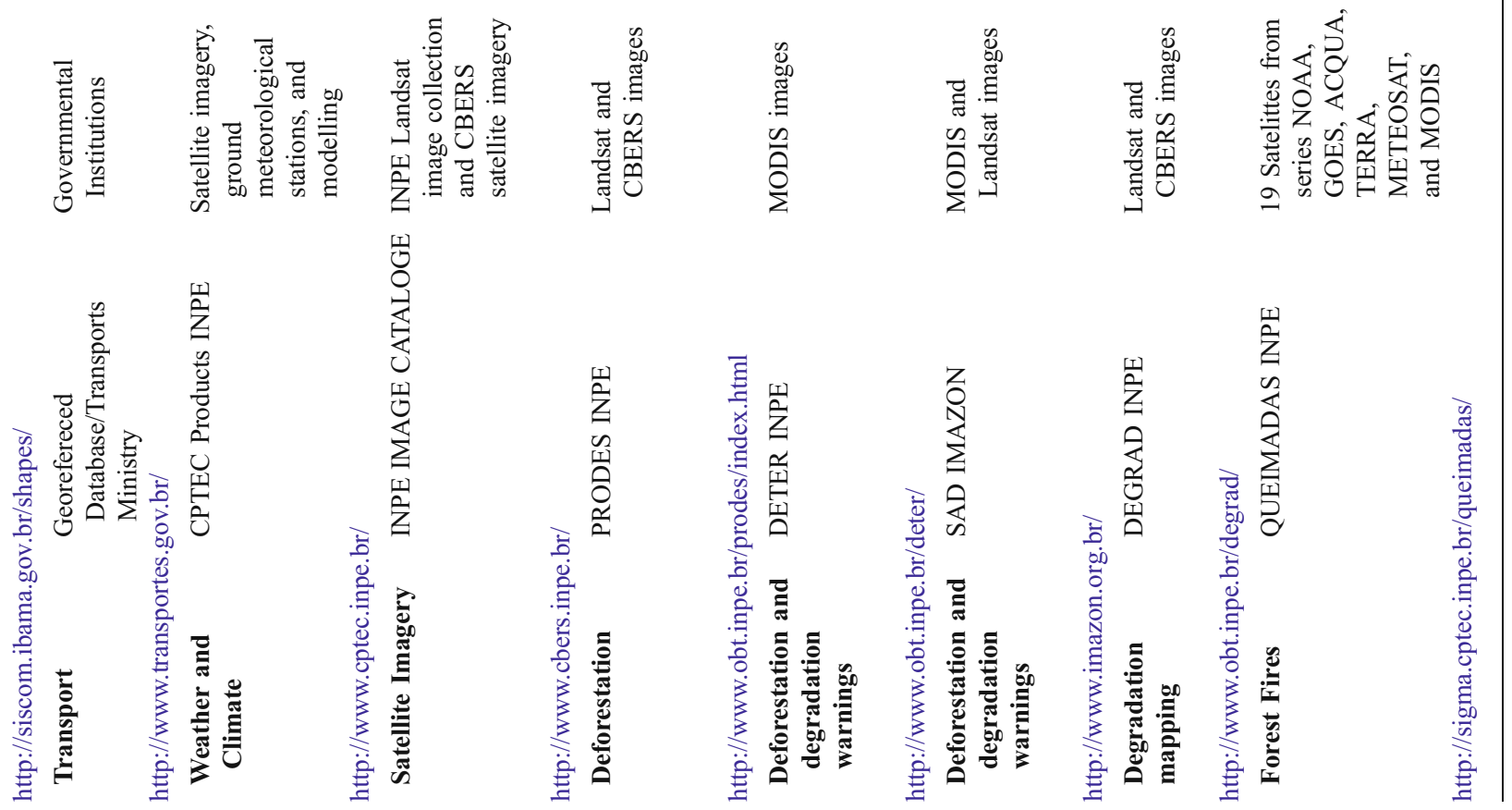
Brazilian Portal of Geospatial Data (SIGBrasil) will be created to access data, metadata, and services related to the Brazilian Directory of Geospatial Data (DBDG). Official geospatial data are supposed to be gathered according to INDE specifications (MundoGEO 2008). Even considering that INDE was enforced by law (Decree $n^{\circ} 6,666$ of 2009/ $11 / 27$, DOU de 28.11.2008), institutes that usually generate geospatial data at operational and at a regular basis will experience difficulties in implementing all the complexity of the metadata required. There are already some initiatives to gather geographical information from Amazonia in spatial database systems for environmental planning and monitoring purposes. Table 2 summarizes these initiatives, and describes them in the following text.

The Ministry of the Environment (MMA) applies different strategies based on open-source tools for environmental geographical data access for Brazil (MMA 2008a). Through the MMA-Geonetwork (MMA 2008b) it is possible to research and, knowing the metadata and the source, to request data from other institutions. They also provide data downloads (from an FTP file list), statistical data access, satellite images from a catalog, and web services clients. Even though searching spatial data for downloads can be time-consuming, the value of the system remains in an updated environmental metadata database.

In 1997, the Brazilian government created a system of shared databases about Amazônia, the BCDAM-Sistemas de Bases Compartilhadas de Dados sobre a Amazônia-a network created to share data among institutions to support the formulation, implementation, and monitoring of public policy and strategies of actions to preserve the natural resources and promote the sustainable development of the Legal Amazonia (MMA 2009). It operates as a network without a particular database infrastructure. Governmental and non-governmental institutions are collaborators, and they are listed as data providers with their respective links. For data visualization, the same Interactive Maps tool from GeoNetwork was adopted.

With the objective of sharing environmental data and, more specifically, for conservation monitoring actions, IBAMA developed the SisCom system-Sistema Compartilhado de Informações Ambientais (IBAMA 2008). SisCom provides the SisCom data viewer, the ability to download satellite images available at IBAMA database, and an FTP list with all environmental data available in the system for the Amazonia region. In spite of the data viewer's limitations, the database and IBAMA monitoring areas can be accessed.

The institution created to protect Amazonia, SIPAMSistema de Proteção da Amazônia, provides an Interactive Map tool where it is possible to select, visualize, and download data from SIPAM projects, and from different institutions as map servers (SIPAM 2008). The system is useful for the municipalities where SIPAM is developing mapping projects at a detailed scale, but the geographical data is available only in pdf format.

To contribute to the protection of the Brazilian Amazon forests, IMAZON developed a spatial data infrastructure oriented to the fields of forest monitoring, conservation and forest law enforcement. The ImazonGEO provides deforestation data from IMAZON (SAD) and INPE (PRODES, DETER and QUEIMADAS), together with basic geographic data from IBGE, IBAMA, INCRA, FUNAI, and IMAZON research data, in a visualization interface used for forest monitoring. It also presents some pre-defined query results, and it is been used as a monitoring tool in the partnership with the Public Ministry for conservation interventions in the state of Pará.

Spatial data generated specifically from research activities in the Amazon region, at several scales, can be accessed from the LBA (Large Biosphere-Atmosphere Experiment in Amazonia) project database (LBA 2008a). Some data are available in FTP file lists (LBA 2008b), and most of them can be accesses with their respective metadata. The access is free for LBA participants, but for common users, a data manager has to be personally contacted. This is an important source of Amazonian data, especially for biogeochemical cycles and climatology data at smaller scales.

To reach a broad and more diverse public, Globo Organizations developed the Globo Amazonia, a system designed to present deforestation and the occurrence of fires in the Amazonia, with associated news. Deforestation warnings and fire foci from INPE, and some articles from Globo are depicted in a Google Earth-like interface. It is very popular, especially among young people, because it allows for some interaction; the system can be plugged in to a relationship system (Orkut) where it is possible to protest against deforestation.

This non-exhaustive list of spatial databases for Amazonia indicates that, even though they were conceived to achieve different objectives, with exception of LBA, the core information is basically the same: geographical reference from the official agencies, and forest monitoring data. Eventually, building those systems resulted in redundant efforts to provide data, especially when considering updating and support to ensure integrity and continuity.

Hopefully, the Brazilian Spatial Data Infrastructure will be able to organize the metadata, standards, protocols and databases. While INDE is not yet fully realized, a suggestion for an ideal system to integrate every spatial database for Amazonia would use MMA/GeoNetwork as metadata reference. A single interactive map provider should be able access and visualize every database and make the data available for download (operating also as a WCS server). It would not entail any data duplication, but it 
would imply that every data provider should be responsible for data sharing and updating. Such an effort would solve the problem of data redundancy and the need to visit several links to build or visualize a consistent database for the Amazonia, at least at a regional scale.

\section{Addressing sustainability and data sharing}

Sustainable development can be defined as "a transformation process where resources are explored, investments are redirected, and technological development is oriented without compromising institutional changes and further demands" (IBGE 2008c).

Spatial awareness is a key issue when discussing sustainability in the Amazon region. The local population has its own mental mapping of a spatial mosaic of land potential and suitability for economic activities. Despite the interest for high profits in the short term and the lack of concern about potential environmental consequences, local worker such as miners, lumbermen, colonists, and farmers have their own knowledge of the surrounding geographic areas. Similarly, scientists, policy makers, and the civil society have a distinct and particular understanding of the same natural space. The notion of sustainability must also address and accommodate different spatial concepts for a defined geographic area, thus converging to a consensus strategy for land occupation in order to ensure the survival of the local population over the long term.

Projects destined to build infrastructure in the Amazon usually bring environmental damages, demographic disturbances, and reductions in quality of life. The Juruti Project (state of Pará), proposed by FGV (Fundação Getúlio Vargas) and ALCOA (FGV 2008), is an example of an attempt to create sustainability following the installation of bauxite mining. A set of sustainability indexes, based on a public consultation of local communities and leaders, will follow the commencement of mining activity. Academies and private initiatives are planning to launch an interactive system to manage geographic and socioeconomic information and to provide open access to the monitoring of sustainability indexes.

Regardless of every infrastructure project, municipalities require adequate systems to plan and to monitor their territories. A system that would make geographic data available and convince people to contribute with field information and their own perspectives of the territory would allow for convergence and sustainability.

A spatial "wiki-like" system could address this challenge, and would be suitable for scientific, governmental and general public interest in the Amazonia. For detailed scales, valuable geographical data are spread over projects and local initiatives. To make those data compatible with a spatial infrastructure, free tools to integrate and share the available data should eventually be available to facilitate geographical data dissemination for such a heterogeneous region.

In a recent fieldwork (June, 2009) of 60 riverine communities at Tapajós River, in the state of Pará, we observed that some communities that did not have access to public energy had Internet access. With budgets from international cooperative projects, they manage to create and maintain a telecenter, with broadband internet access and informatics classes, in a place where public telephones only work once every 3 days. The level of community organization is directly related to the social and infrastructure conditions. A system that could plot these communities in the world map would help them to improve. It could start with a simple system were communities could indicate their main needs, similar to the fire spots in the Globo Amazonia system. For every community point (2007 Agronomical Census, available at IBGE 2009), the community president could post, for example, a photograph showing their needs, such as the need of a health center or a condition in a school that is dangerous. They could also post a document stating a requirement, as shown in Fig. 1.

The community of Suruacá, at the left margin of Tapajós River had an health station approved, but the construction was delayed by 20 years. They created a document, with the signatures of the inhabitants, demanding their rights to the health center be met. By gaining the attention of the general public, the demand may be satisfied more easily, and by posting their demand, it would only be applied based on the legitimacy of the association of inhabitants.

A more sophisticated system could be projected to work with both sides, to register the communities' demands, and to help the municipal administration plan and monitor, such as, for example, the investments in health, by recording data on people treated at a health center, and in education, with the students' performance.

The dissemination of sustainability information would actually create options for the local economy and alternative productive chains, such as non-woody forest products (medicinal products, essential oils, handcraft, native fruits, bio-fuel, etc). A system that could report and publish successful examples of sustainable economic chains in Amazonia would also favor the growth of the forest products market and the usage of goods and services.

Another possible system, in which each landowner could distinguish the boundaries of their properties, and define their limits using high-resolution satellite imagery, would also be useful to monitor land use, and deforestation activities at property-level scales. This type of system could be useful to a discussion regarding carbon credits and possible ways to make the credits profitable to the counties. 


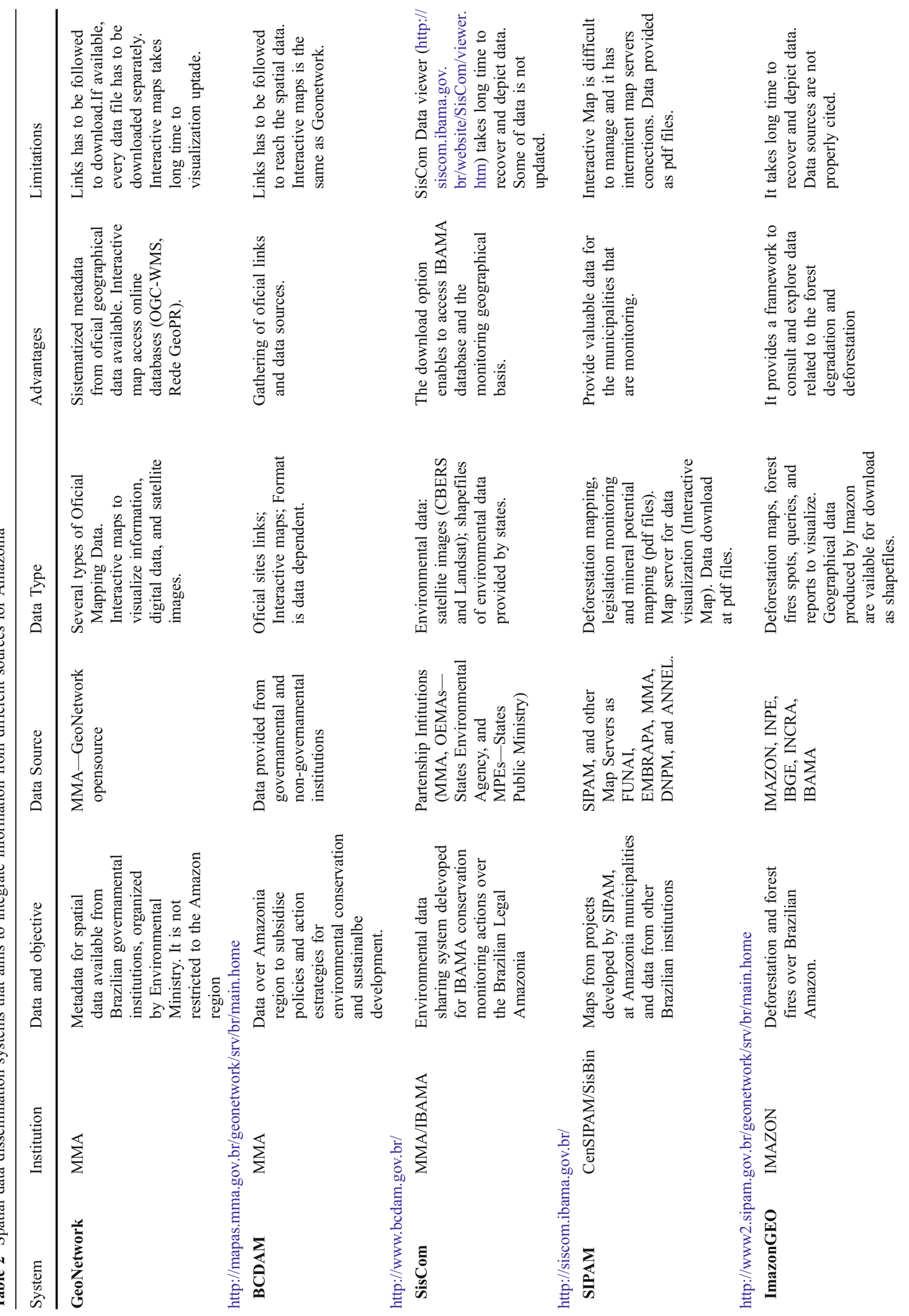



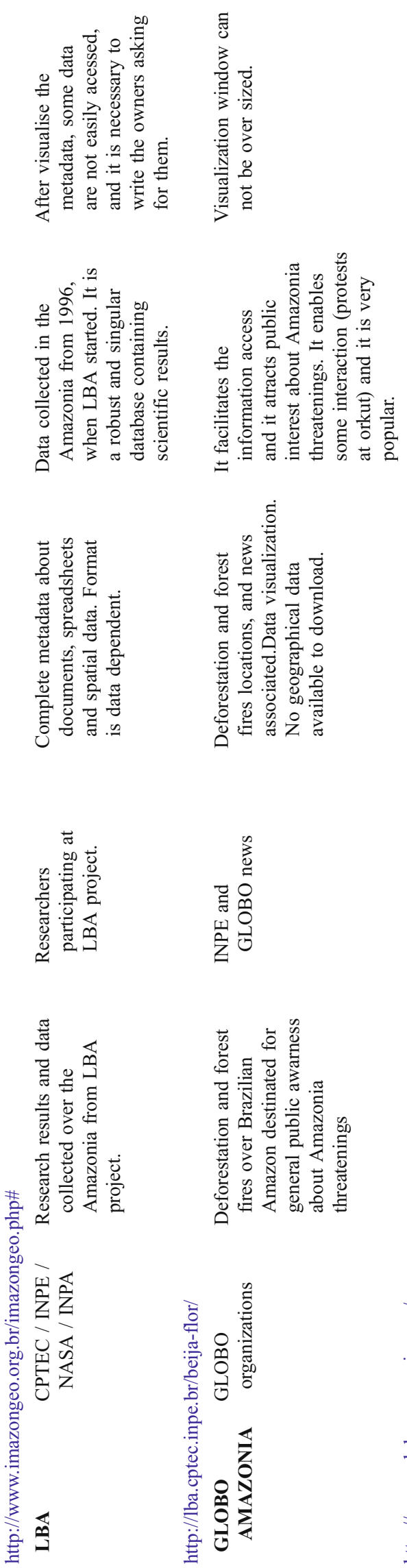

To incentivize data sharing and to improve the knowledge about Amazonia, the scientific community should also contribute to general information. When studying the Amazon region, to incorporate spatial data at detailed scale, researchers must generate the data, including fieldwork to collect data, and they also have to measure the variables or personally request the data from the producer (local government institutions or agencies). Fieldwork in Amazonia is fundamental, but is also very expensive and timeconsuming, and, in some cases, involves health hazards for the researches (tropical diseases, land conflicts, among others). Nevertheless, is not rare that different groups attempt to send expeditions to the same field areas. The redundancy of effort and waste of the budget could be minimized if photographs, descriptions, and field data, all of which have precise geographical coordinates could be published in a system similar to the field work photographs database (Fig. 2) from INPE (INPE 2009e).

This type of initiative is complementary to the scientific database provided by LBA because there is spatial information available to the general public. It would not replace fieldwork, but would surely optimize its planning and a general overview of the land use dynamic.

\section{Final remarks}

We presented a general overview about the availability of spatial data in Amazonia, considering the primary data distribution and some initiatives of data dissemination. At a regional scale, the institutes that generate the basic cartography also make the geographical data available. Gathering all the useful basic spatial data can be a difficult task, but it is feasible with an adequate Internet access and perseverance. Existing data dissemination initiatives appear to meet the proposed objectives, such as environmental monitoring, control of deforestation, promoting public awareness about forest conservation, or sharing data between institutions.

From these already established initiatives, data dissemination for general users could be facilitated. All the interactive map tools lack the ability to visualize and access data. Based on an already operational metadata database (MMA/GeoNetwork), it would be very worthwhile to have the map servers joined in a single interface for visualization, selection, and data downloading. Official data providers could guarantee data updating and data access.

Internet access is more prevalent than basic public sanitation in Brazilian villages. Considering that geographical information is a catalyst to promote organization and sustainable development in the Amazonian region, we presented some thoughts about spatial interactive systems. Spatial "wiki-like" interactive systems could be constructed 
Fig. 1 The Saruacá community position (IBGE 2009), and the document demanding the construction of their already approved Health Center at Santarém Mayor
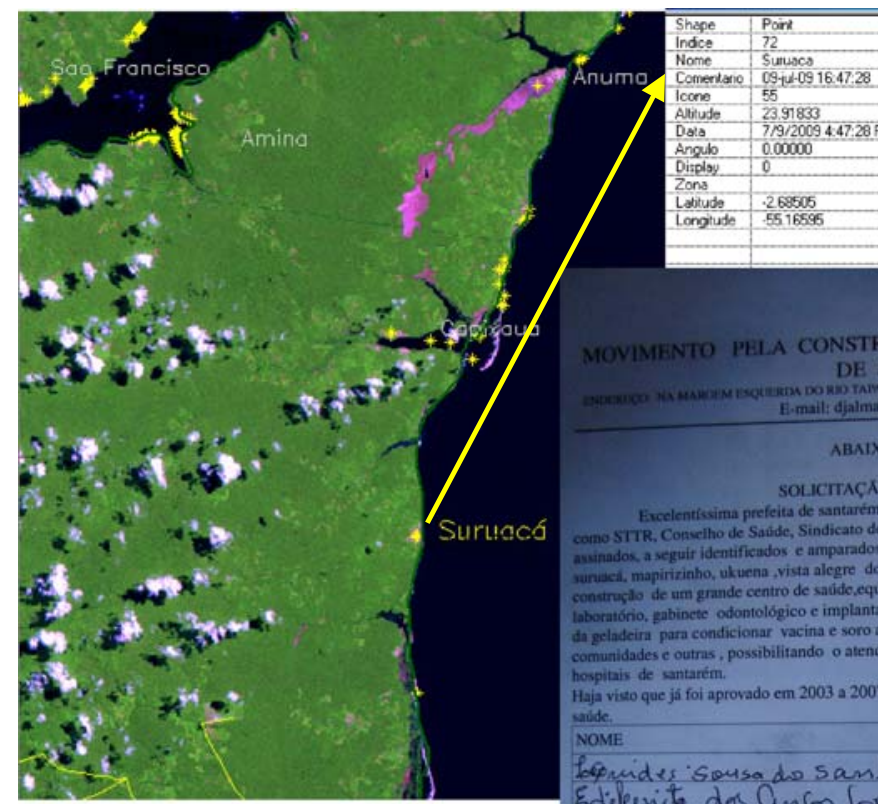

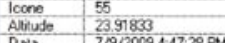

\begin{tabular}{lll} 
Dols & $7 / 9 / 200$ \\
\hline Anoib & 000000
\end{tabular}

\begin{tabular}{ll} 
Anoulo & 0.000 \\
\hline Ditploy & 0 \\
\hline Zond
\end{tabular}

\begin{tabular}{ll} 
Zond & \\
\hline Lotude & .268505 \\
\hline
\end{tabular} \begin{tabular}{l} 
Latude \\
Longitude \\
\hline 55516595 \\
\hline
\end{tabular}
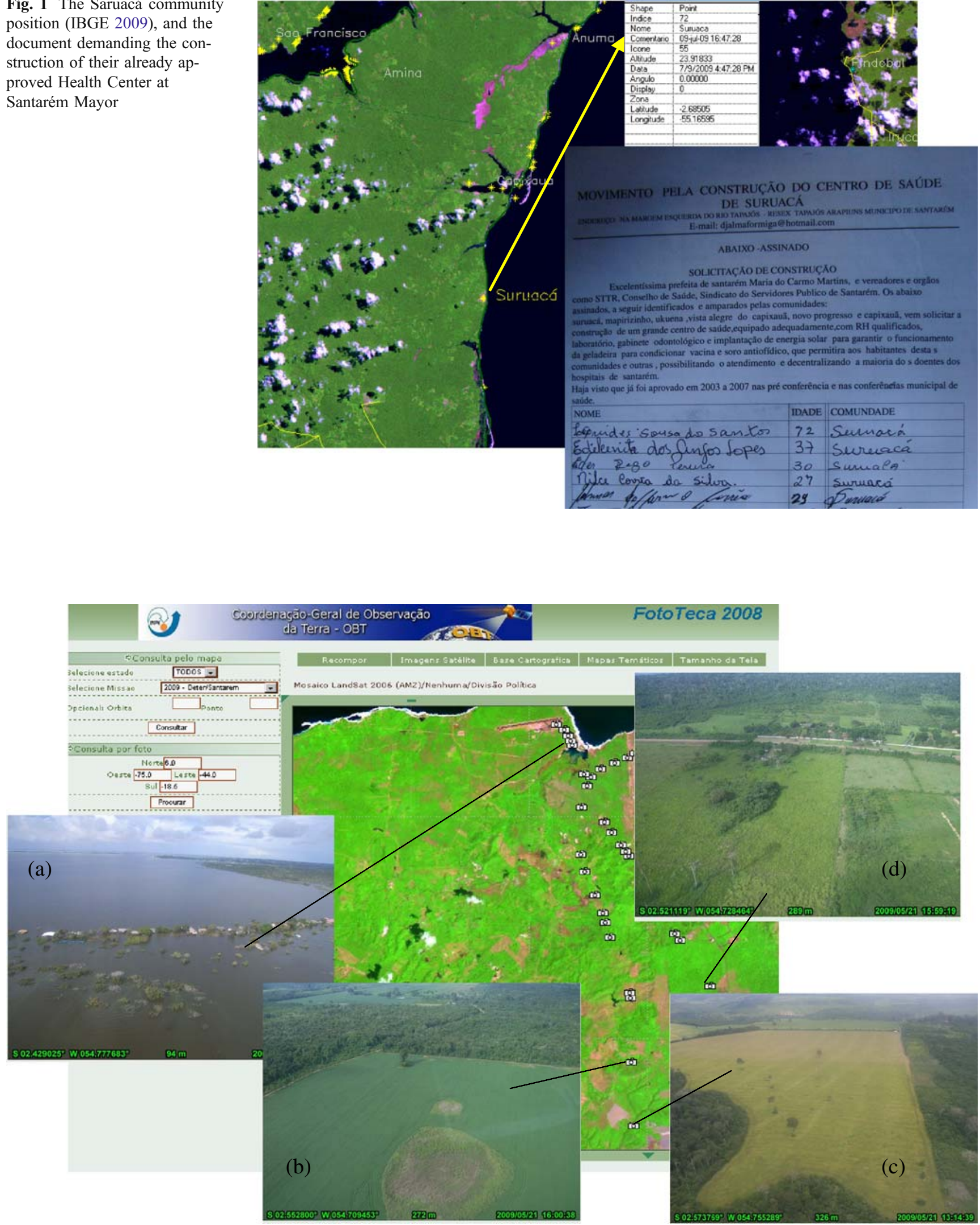

Fig. 2 Example of data available at INPE's fieldwork photographs database. Photos taken during helicopter flight over Santarém-PA (may/2009) with GPS coordinates. The effect of high waters over settlements (a), two stages of soybean plantations between forest remnants (b and $\mathbf{c}$ ), and pasture/pepper plantation in a region of small farmers (d). Source: INPE 2009e 
to use information to benefit the local community, and at the same time, allowing for social organization. Some examples of systems where the populations could learn about their environmental condition, or express the needs of the local population, or even advertise their sustainable industries could assist in environmental conservation and improvement in quality of life.

The limitation on promoting spatial information and data sharing in Amazonia is neither computational nor technological. Rather, it is a matter of educating those who create the data about the benefits of knowledge as a public good and promoting collaborative works. Creating a convergent spatial consciousness about the territory and bringing together every environmental player, is a step towards the discussion and planning of sustainable development in the Amazonia.

\section{References}

FGV (2008) Projeto JURUTI. Projeto Diagnóstico e Monitoramento do Desenvolvimento de Juruti e Entorno, 2008, Available at http://indicadores.gvces.com.br/index.cfm?fuseaction=conteudo\& idSecao $=58$. Accessed 2008.

Herbarium MG (2008) Herbário do Museu Emílio Goeldi, Available at http://marte.museu-goeldi.br/herbario. Accessed 2008.

IBAMA (2008) SISCOM. Sistema Compartilhado de Informações Ambientais, Available at http://siscom.ibama.gov.br/. Accessed 2008.

IBGE (2008a) Contagem da População 2007. Sistema de Recuperação Automática - SIDRA. http://www.sidra.ibge.gov.br/. Accessed 2009

IBGE (2008b) Instituto Brasileiro de Geografia e EstatísticaMAPAS, Available at http://www.ibge.gov.br/mapas_ibge/. Accessed 2009.

IBGE (2008c) Instituto Brasileiro de Geografia e EstatísticaIndicadores de desenvolvimento sustentável. Estudos \& Pesquisas, Rio de Janeiro

IBGE (2009) Instituto Brasileiro de Geografia e Estatística-Censo Agropecuário 2007. Available at http://www.sidra.ibge.gov.br/

INPA (2008) Herbário do INPA, Available at http://angelim.inpa.gov. br/. Accessed 2008.

INPE (2009a) Monitoramento da floresta amazônica por satélite, Projeto PRODES, Available at http://www.obt.inpe.br/prodes. Accessed in 2009.
INPE (2009b) Sistema DETER. Detecção de Desmatamento em Tempo Real. Available at http://www.obt.inpe.br/deter. Accessed in 2009.

INPE (2009c) DEGRAD - Mapeamento da Degradação Florestal na Amazônia Legal. Available at http://www.obt.inpe.br/degrad. Accessed in 2009.

INPE (2009d) QUEIMADAS-Monitoramento de Focos. Available at http://sigma.cptec.inpe.br/queimadas/ Accessed in 2009.

INPE (2009e) FOTOTECA. Banco de Dados de Fotos de Campo. Available at http://www.obt.inpe.br/fototeca/fototeca.html. PIME- Tapajós. Accessed in 2009.

LBA (2008a) Beija-flor Search Engine for the LBA Project, 2008, Available at http://lba.cptec.inpe.br/beija-flor/. Accessed 2008.

LBA (2008b) LBA Data Access-New User Registration, 2008, Available at https://daac.ornl.gov/new user.shtml. Accessed 2008.

MMA (2008a) Mapas - GeoNetwork, Available at http://mapas.mma. gov.br/geonetwork/srv/br/main.home. Accessed 2008.

MMA (2008b) MMA Geoprocessamento, Available at http://www. mma.gov.br/index.php?ido $=$ conteudo. monta\&idEstrutura $=41$. Accessed 2008.

MMA (2009) Bases Compartilhadas de Dados sobre a AmazôniaBCDAM, Available at http://www.bcdam.gov.br/. Accessed 2009.

MOBOT (2008) TROPICOS-Missouri Botanical Garden, Available at http://www.tropicos.org/. Accessed 2008.

MundoGeo (2008) Decreto institui a Infraestrutura Nacional de Dados Espaciais no Brasil, Available at http://www.mundogeo.com.br/ noticias-diarias.php?id_noticia=12426. Accessed 2008.

NYBG (2008) International Plant Science Center. The C.V. Starr Virtual Herbarium, Available at http://sciweb.nybg.org/science2/ VirtualHerbarium.asp. Accessed 2008.

PPBIO (2008) PPBio Research Program in Biodiversity-Metadata and data, Available at http://ppbio.inpa.gov.br/Eng/dadosinvent/. Accessed 2008.

Presidência da República (2008) Decreto 6666, Available at http:// www.planalto.gov.br/ccivil_03/_Ato2007-2010/2008/Decreto/ D6666.htm. Accessed 2008.

RAINFOR (2008) Amazon Forest Inventory Network-Rainfor, Available at http://www.geog.leeds.ac.uk/projects/rainfor/. Accessed 2008.

SIPAM (2008) AMAZONIAN PROTECTION SYSTEM-SIPAM, Available at http://www.sipam.gov.br. Accessed 2008.

Souza CM Jr, Hayashi S, Verissimo A (2009) Near real-time deforestation detection for enforcement of forest reserves in Mato Grosso. Land Governance in Support of the Millennium Development Goals: Responding to New 40 Challenges, Washington DC, USA, World Bank 